\title{
Privatising health: the demise of MEDICARE?
}

\author{
Beth Cook
}

\begin{abstract}
Health policy was an integral component of the post-war welfare state, which represented a nationally based class compromise providing concessions in the form of income support and service provision outside the ambit of the market. In Australia, development of a universal health system was delayed until the introduction of Medibank, and subsequently Medicare. Since its inception, Medicare has been subjected to retrenchment pressures that have dominated welfare state developments since the mid 1970s. This paper traces developments in the Australian health system, revealing that the major trends, privatisation and the transfer of responsibility from the collective to the private sphere, represent a movement towards a more residual system that threatens the Medicare goal of equitable access to quality medical treatment.

Keywords: Health care reform, Medicare, Welfare state
\end{abstract}




\section{Introduction}

Along with other aspects of the welfare state, health systems internationally have encountered retrenchment pressures over the past three decades as accelerating costs coincided with the introduction of neo-liberal economic policies privileging private enterprise, small government and tax cuts. As Shaoul points out, governments have curtailed public sector expansion, implicitly or explicitly promoting the re-privatisation of health provision:

Healthcare 'reforms' - the introduction of financial targets, quasi-markets, creeping privatisation, public-private partnerships, outsourcing of 'non-core' services, hospital and ward closures, user charges, 'targeting', cuts in funding and social division - are being introduced by governments of every political persuasion in every country at the behest of the financial markets and giant corporations. (Shaoul, 2003: 146)

This paper examines developments since the introduction of Medicare, an integral component of the welfare state. In particularly it traces the process of 'privatising': the shift from public to private provision and funding through subsidisation of private health insurance, under-funding public hospitals, and increased co-payments. These developments represent an unequivocal retreat from the principle of universal health care, and constitute retrenchment of a fundamental aspect of the welfare state.

\section{What is the welfare state and what constitutes retrenchment?}

The international welfare state emerged in the postwar period, providing broadly similar welfare measures in industrialised countries, despite differences attributable to historical developments, philosophical outlooks, economic and social organisation. Its defining characteristic was an over-arching government commitment to accept responsibility for providing a socially determined level of welfare by: a) maximising employment, the primary means for the majority of the population to secure welfare and facilitate societal participation; b) ameliorating market outcomes to ensure minimum living standards through progressive taxation, access to services, and income support for those either unable or not expected to support themselves through market activities; and c) recognising entitlement through access as a right of citizenship.

The necessity for retrenchment has been attributed to financial constraints due to globalisation which dictates the destruction of working conditions and social provision to maximise international competitiveness (Faux and Mishel, 2000), and demographic pressures (Hirst and Thompson, 1999). A concomitant assault on values such as collective responsibility, universalism, equality and social solidarity attempted to justify transferring responsibility from the social to the individual sphere, that is, to 'legitimate' retrenchment. Governments and right-wing think tanks, along with international bodies such as the IMF, OECD and World Bank, have championed returning functions to the market through deregulation and privatisation and advanced the 'moral imperative' that individuals accept responsibility for welfare provision, claiming that those who can afford to pay for services have an obligation to do so. Notwithstanding concerted attempts to undermine public support, opinion polls internationally indicate strong support for most welfare state programs and overwhelming support for health and education. 
Welfare state retrenchment encompasses: a) programmatic changes that either cut social expenditure or restructure welfare state programs to conform more closely to the residual welfare state model, and b) systemic changes that alter the political environment in ways that enhance the probability of such outcomes in the future (Pierson, 1994). Components of programmatic retrenchment include reducing or suspending indexation of benefits, or restricting access by tightening eligibility. Systemic retrenchment includes reducing the funding base, weakening pro-welfare state groups either through privatisation or attempting to change public opinion, and introducing institutional change.

\section{Overview of the Australian health system}

\subsection{Introduction}

The configuration of the Australian health system is the legacy of a predominantly private system, overlaid with an incomplete universal health insurance system. It retains many historical characteristics, including coexistence of public and private hospitals as well as private sector, fee-for-service provision of medical services.

Introduced by the Hawke Labor government in 1984 as an integral component of the social wage under the Prices and Incomes Accord, Medicare promised access to high quality, affordable health care based on clinical need. Medicare comprises the Medicare Benefits Scheme (MBS) for services provided by medical practitioners, subsidised medicines through the Pharmaceutical Benefits Scheme (PBS), and public hospital funding through the Australian Health Care Agreements (AHCAs), and is funded according to ability to pay, combining general revenue with a levy on taxable income. According to Scotton and Macdonald (1993: 265), 'even under Medibank and Medicare, the Australian health system lies at the 'more private' end of the mainstream international spectrum'.

\section{Figure 1: Australian health care funding 1974-75 to 2001-02}

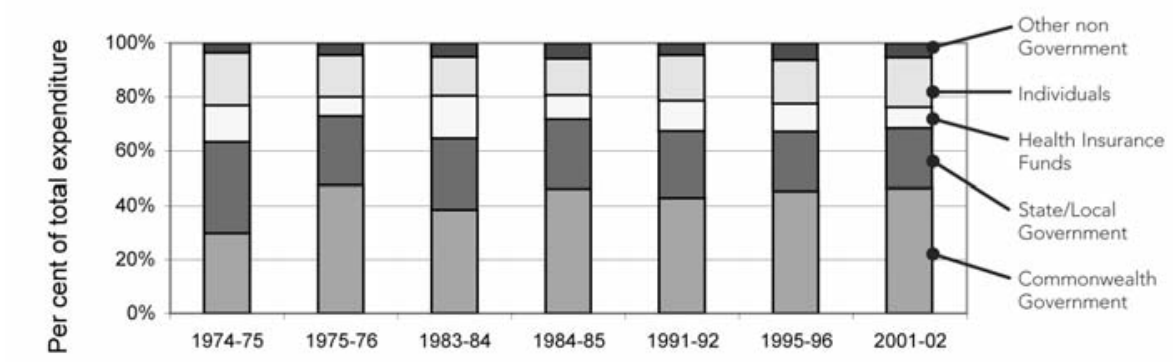

Source: AlHW (2003) National health expenditure, current prices.

Government funding increased substantially after the introduction of Medibank and Medicare (Figure 1). Between 1984-85 and 2001-02 the Commonwealth funding share remained constant at 46 per cent. However, declining State and private health insurance (PHI) shares were counterbalanced by an increased funding burden for individuals (from 13.6 to 18.4 per cent). 


\subsection{Public hospitals}

Shared funding responsibility combined with fiscal constraints imposed by governments, has resulted in conflict, cost- and blame-shifting between Commonwealth and State governments in the public hospital sector, as well as impeding accountability for service inadequacies. The system has provided cost-shifting opportunities for States; bulk-billing or cutting outpatient services, thereby transferring costs to the MBS.

Conversely, State governments have complained of insufficient Federal funding or indexation to cover real wage rises, technological change, population ageing and increased demand for health care, while larger States have criticised disproportionate funding to smaller states under fiscal equalisation arrangements (Donato and Scotton, 1998). In the late 1990s, increased emergency department attendances coincided with falling GP bulk-billing rates, suggesting cost-shifting from the MBS. Similarly, workforce shortages and the increase in elderly patients due to lack of aged care places have been attributed to Commonwealth policies (Ross et al., 1999).

Commonwealth/State responsibilities are enshrined in Australian Health Care Agreements (AHCAs) which the Commonwealth has increasingly used to influence State expenditure and service decisions. Since 1988 Medicare Agreements have included provisions to reduce grants to States in specified circumstances. Triggers for funding restrictions have included: above average private hospital utilisation; in-hospital MBS payments exceeding the national average by more than five per cent; increases in the share of private patients or reductions in the share of public bed days; failure to provide the minimum prescribed level of public hospital services; and in the current agreement, maximum funding is contingent on states matching the cumulative rate of growth of Commonwealth expenditure. Other initiatives in Medicare Agreements have included attempts to increase the proportion of day surgery and access to elective surgery for public patients; reduce waiting times; and institute mental health, Aids, post-acute and palliative care programs. However, these initiatives have been insufficient to address population needs due to funding restrictions.

The link between PHI and public hospital demand was formally recognised in the 1993-98 agreement provision for a funding review if supplemental hospital insurance coverage fell more than 2 per cent from the June 1993 level. Due to persistent concerns about falling PHI membership, State governments negotiated increased/decreased funding between 1998 and 2003 if PHI membership fell/rose.

\subsection{Privatising public hospitals}

Despite accelerating costs associated with technical innovations and wage rises, public hospital expenditure remained static at 2.3 per cent of GDP between 1983-84 and 2001-02, contrasting private hospital growth from 0.4 to 0.7 per cent of GDP (AIHW, 2003). From 1987-88 to 2002-03 hospital beds per 1,000 population declined by over 35 per cent for public acute hospitals, but increased by 5.4 per cent for private hospitals, reflecting the rising proportion of private provision.

Creeping privatisation policies that shift resources from public to private hospitals have been combined with overt policies including: contracting out services such as catering, cleaning, maintenance, laundry, car parks, security, radiology and pathology, and more 
recently, utilisation of Public-Private Partnerships (PPPs) to transfer responsibility for financing, building, owning and operating some public hospitals to the private sector.

The 1998-2003 AHCA provision authorising provision of public hospital services in 'any appropriate environment' facilitated treatment of 98,527 public patients in private hospitals in 2002-03 (Australian Institute of Health and Welfare, 2004). Individual services have been contracted to the private sector: maternity services in Bernie, ophthalmology in Hobart, urology services in the Illawarra, and public day surgery, step-down care and cardiac catheterisation in Flinders Medical Centre.

In recent years, State governments have engaged in various forms of Public-Private Partnerships (PPPs) to operate public hospitals and/or provide infrastructure off balance sheet. PPPs are justified by claims of higher productivity and greater innovation in the private sector, public sector funding constraints, and risk transfer. However, Sperling and Parslow (1999: 82) contend assessments of potential savings should include costs of disputes, bargaining, transactions and monitoring, and that 'Governments must retain the capacity to provide comparable services or to engage alternative providers if they are to ensure value from contracts with private operators'.

Various types of PPP have proceeded in Australia: a) Build, Own, Operate (BOO), where the private operator retains ownership of the hospital when the contract expires (Port Macquarie, NSW; Latrobe, Victoria); b) Build, Own, Operate, Transfer (BOOT), involving private construction and operation, followed by ownership transfer to the public system after the contract expires (Hawkesbury, NSW; Noosa, Queensland; Joondalup, Western Australia): and c) Build, Own and Lease Back (BOLB) involving private construction and ownership with the government leasing and operating the hospital (Mt Gambier, South Australia).

The balance of Australian evidence indicates that the promised financial benefits of PPPs have not been realised. An Auditor General review of Joondalup hospital found the process failed to establish that PPP would deliver net tangible benefits over a public sector alternative (Auditor General, 2000: 7). Post implementation comparisons with benchmark hospitals, found patient satisfaction ratings for Joondalup were inferior, particularly relating to availability of staff, continuity of care and being kept informed. Moreover, contract omissions necessitated renegotiation and additional payments. Also, the Metropolitan Health Service Board (MHSB) claimed that bed block at inner city hospitals resulted from Joondalup's reluctance to accept patient transfers due to financial arrangements (Auditor General, 2000: 23).

The Port Macquarie Base Hospital (PMBH) failed to produce the estimated \$46 million cost savings, and contract omissions necessitated significant additional payments (for details, see Collyer, 1997). The NSW Auditor General reported that the government would pay twice for the cost of capital construction; in the annual availability fee and through fee-for-service payments, but would own neither the land nor the buildings. Collyer (1997: 35) concluded:

The increasing support for privatisation, despite its poor fiscal outcome to the state, can best be explained with recourse to the theory of privatisation as a prevailing, pervasive discourse which favours the interests of powerful groups and institutions - particularly financial corporations and the political arm 
of the state ... and it hides the fact that privatisation is actually a transfer of public wealth to the private sector.

The sale of PMBH to Affinity Health Limited in 2003 provoked a dispute with the State government, culminating in the 2005 purchase of the hospital by the NSW government for $\$ 29$ million.

In addition, unsuccessful privatisation attempts have resulted in hospitals reverting to public ownership and/or operation, raising questions regarding the extent of risk transfer to the private sector. These include Berwick Community Hospital and Latrobe Hospital in Victoria, and Robina Hospital in Queensland.

Repatriation General Hospital in Western Australia, Lady Davidson in NSW, and Repatriation General Hospital in Queensland were privatised in the mid 1990s as part of the Department of Veterans Affairs' divestment program. Private hospital treatment for veterans increased from 16.7 per cent of total DVA hospital expenditure in 1992-93 to 32.4 per cent in 1996-97 due to the increase in the number of private hospitals providing services to DVA patients; from 192 in 1991-92 to 275 in 1996-97 (Sperling and Parslow, 1999: 88).

Finally, the distinction between public and private hospitals has become blurred by the trend toward co-location, which provides significant benefits to the private hospital such as lower operating costs for pathology, radiology, laundry, catering and parking, as well as facilitating access to expensive equipment (Sperling and Parslow, 1999).

\subsection{The private hospital sector and private health insurance}

The increasing private hospital share is the most striking trend in the hospital sector during the past two decades. In Australia, discussion regarding private-public sector balance has been conflated with the issue of PHI. This section traces private hospital and PHI developments arguing that the increase in private hospital share can be attributed to the drive for profit by the private sector, coupled with government attempts to limit public sector growth and shift costs to individuals.

The role of private hospitals remains contentious in Australia. According to Deeble (2003), private hospitals and PHI were originally supplementary to Medicare, allowing people to 'opt-up' but not 'opt-out' by facilitating access to choice of doctor and hospital, flexible access, and ancillaries. In recent years, government arguments that increased PHI coverage would take pressure off public hospitals fostered the view that private hospitals are alternatives to Medicare.

Problems afflicting PHI in the 1990s included: rapidly increasing premiums, declining membership, adverse selection and moral hazard, complexity, high levels of regulation and out-of-pocket expenses (National Health Strategy, 1991; Industry Commission, 1997). PHI membership declined from almost 49 per cent of the population in June 1986 to below 32 per cent by June 1997, reaching an annual rate of decline of 5.5 per cent between 1991 and 1995, and was concentrated in younger age groups (declining 46 per cent for those under 25 and 43 per cent for those 25 to 34 between 1980 and 1990). 
Figure 2: Private hospital utilisation and PHI membership (per cent)

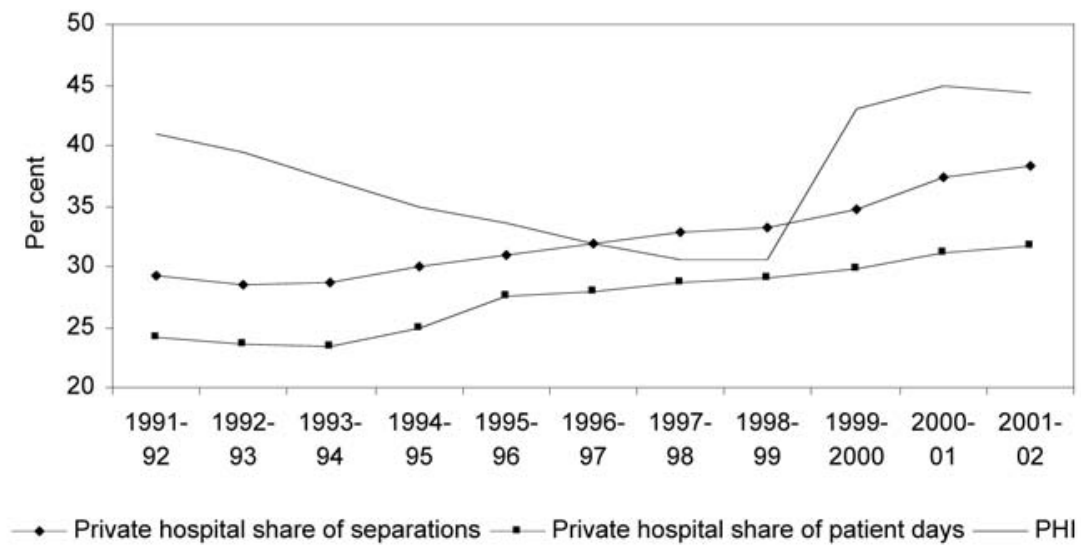

Source: PHIAC (2003) Statistical trends in membership and benefits; AIHW, National Health Expenditure

However, the argument that declining PHI membership represented a crisis in the private hospital sector is difficult to maintain since it coincided with a shift from public to private hospital provision (Figure 2). The private hospital share of separations increased from 29 per cent in 1991-92 to 33 per cent by 1998-99, while patient days increased from 24 per cent to 29 per cent.

\subsection{Government promotion of PHI}

Governments have sought to institutionalise a two-tier system by promoting private hospital treatment for those able to afford PHI, relegating public hospitals to a welfare safety net. Major arguments privileging private sector treatment include: relieving pressure on the public system; efficiency gains from subsidising the private rather than expanding the public sector; and enhanced consumer choice (see Duckett and Jackson, 2000; Deeble, 2003; OECD, 2003).

The Keating government attempted to bolster PHI in 1995 by permitting funds to enter into contracts with providers and offer 100 per cent cover. Since its election in 1996, the Howard government has implemented three major policy initiatives to promote PHI. First, in July 1997 the Private Health Insurance Incentives Scheme (PHIIS) provided a rebate for low income earners with PHI and imposed a penalty of one per cent of taxable income for high income earners without PHI. Failure to index the surcharge threshold represents privatisation by stealth, automatically incorporating an increasing proportion of the population over time.

Secondly, the January 1999 introduction of the Private Health Insurance Rebate (PHIR), a non-means-tested 30 per cent rebate on all PHI contributions, constituted a major compositional change in Commonwealth health expenditure. The surcharge for high income earners remained and health funds were required to offer 'no-gap' or 'known-gap' policies by July 2000. Commonwealth expenditure on the uncapped PHI rebate increased from $\$ 1.5$ billion in 1999-2000 to $\$ 2.5$ billion by 2003-04. 
Finally, Lifetime Health Cover (LHC) was introduced in July 2000 to boost the take-up rate of PHI, improve the risk profile and ensure continuity of membership by imposing a premium surcharge of 2 per cent for each additional year of age over 30 at the time of entry, up to a maximum surcharge of 70 per cent. The introduction of LHC was accompanied by an $\$ 8.7$ million 'run for cover' advertising campaign that played on fears of inadequate future access to public hospitals generated by media coverage highlighting the crisis in the public hospital system (see Hall, 2001 for details of media coverage of health issues). In response to the ALP Medicare Gold policy during the 2004 election campaign the government increased the rebate for older Australians, to 35 per cent for those over 65 , and 40 per cent for those over 70 years.

The Industry Commission (1997: 29) noted the privatising motivation behind government promotion of PHI:

Through supporting private health insurance, and by providing incentives in response to this pressure, the Government is endeavouring to switch health funding from the public sector to private sources. This process is also aided by the expenditure constraints imposed on the public health system in recent years, reflected in constrained access to public hospitals.

PHI membership increased from 30.2 per cent in December 1998 to 45.7 per cent in September 2000, prompting Prime Minister Howard to declare 'we have revived from its death throes private health insurance' (Howard, 2001). However, PHI membership subsequently declined to 42.9 per cent in September 2005, with the fall concentrated in younger age groups. Several analysts claim that pressure on the public system has not been reduced and may have been exacerbated due to inelastic supply (for more information see Deeble, 2003; 2002; McAuley, 1999; 2003; 2005; Richardson, 2003). The rebate produces pro-rich inequity since low income earners subsidise the better off who by-pass queues for elective surgery.

Furthermore, the combined effect of abolition of the means-tested Commonwealth Dental Health Program (CDHP) in 1997 and the introduction of the 30 per cent rebate on PHI premiums in 1999 was to effectively remove access to dental care for many low income Australians and transfer subsidised dental treatment to higher income earners with PHI, or given the oral health gradient, from the most to the least needy. Spencer and Harford (2003) claim that a dental program for concession card holders, estimated to cost $\$ 446$ to $\$ 611$ million in 2001 , could have been funded by combining State dental program expenditure of $\$ 253$ and Commonwealth subsidies for dental treatment for PHI members (\$317 million through the 30 per cent rebate and \$23 million through tax rebates).

\subsection{Medicare Benefits Scheme (MBS)}

The MBS underpins medical treatment in Australia. The Commonwealth has attempted to control expenditure by shifting the incidence of fees to individuals, controlling the supply of doctors, and some movement toward combined fee-for-service and fixed payments. The Medicare levy increased from 1 per cent of taxable income in 1984 to 1.25 per cent in 1986, 1.4 per cent in 1993, and finally 1.5 per cent in 1995 . Maximum patient contributions for medical services have increased and in 1987 the Medicare 
rebate for medical services to private hospital patients was cut from 85 per cent to 75 per cent of the schedule fee.

Several initiatives have sought to control uncapped MBS expenditure. Schedule fees were reduced for pathology and imaging in the 1980s, annual growth in pathology costs was restricted to 6 per cent from 1996, and psychiatric consultations were limited from 1996-97. Also, the General Practice Strategy moved away from an exclusively fee-for-service approach from 1992, although Sperling and Parslow (1999: 26) claim that measures to limit supply and supplier-induced demand have had limited success. Not all retrenchment attempts have succeeded. Opposition to the imposition of co-payments for bulk-billed services in 1991 and the 1993 attempt to remove Medicare benefits from most optometric consultations meant that these measures were politically unsustainable.

\subsection{Bulk-billing}

Bulk-billing is fundamental to needs-based access to medical care; therefore, to a large extent bulk-billing rates are a proxy for the health of the MBS. Bulk-billing rates are determined by a combination of factors, primarily the rebate level relative to increased costs, wages and the CPI, and the level of supply of doctors.

Table 1 shows that bulk-billing rates increased until the mid 1990s then declined, with the exception of optometry and pathology. Bulk-billing rates for GP visits increased from 52.5 per cent in 1984-85 to peak at 80.1 per cent in 1995-96 before declining to 68.2 per cent in 2003-04. Similarly, between 1995-96 and 2004-05 bulk-billing rates declined for specialists (32.5 to 26.3 per cent) and for obstetrics (26.3 to 21.9 per cent).

Figure 3 shows that between 1984-85 and 2001-02 the schedule fee stagnated in real terms and fell significantly relative to real average weekly earnings. GP incomes declined from 5.2 times average weekly ordinary time earnings (AWOTE) in 1994-95 to 4.7 times AWOTE by 2002-03, coinciding with the marked decline in bulk-billing rates and increase in out-of-pocket expenses.

Supply is also a major factor impacting on bulk-billing rates. Testimony before Senate Committee hearings in 2003 repeatedly stressed the inverse relationship between the supply of doctors and bulk billing rates (Senate Select Committee on Medicare, 2003a; b). Since 1996, Commonwealth restrictions on Medicare provider numbers and training places restricted GP supply despite Australian Medical Workforce Advisory Committee concerns that significant GP shortages resulted in poor access, unmet need, potentially poorer health outcomes, and overworked doctors (Harding, 2000). Incentive programs to address inequitable distribution have encouraged greater supply in rural and remote areas and restricted growth in urban areas.

Given overwhelming public support for Medicare, inroads into bulk-billing availability have been politically possible because of the difficulty of unravelling the complex interaction of private medical practice and policy decisions to restrict supply and reduce real rebates. For example, Prime Minister Howard stated that between 1996 and 2001 the number of bulk-billed services increased (The Howard Government, 2001) but failed to mention that the proportion of services bulk-billed declined for both GP and specialist consultations. Despite improvements since the introduction of Medicare Plus, the bulk-billing rate for medical consultations remains significantly lower than in 1995-96. 
In addition, between 1984 and 2002-03 real out-of-pocket expenses for non bulk-billed patients increased by 44 per cent (Senate Select Committee on Medicare, 2003b).

Table 1: Bulk-billing rates $1984-85$ to $2003-04$

\begin{tabular}{cccccccc}
\hline Year & GP & Specialist & Obstetrics & Optometry & $\begin{array}{c}\text { Diagnostic } \\
\text { Imaging }\end{array}$ & Pathology & Total \\
\hline $1984-85$ & 52.5 & 21.2 & 16.2 & 68.2 & 34.3 & 43.7 & 45.2 \\
$1995-96$ & 80.1 & 32.5 & 26.3 & 94.5 & 61.3 & 76.1 & 71.1 \\
$2003-04$ & 68.2 & 26.7 & 20.5 & 96.6 & 57.9 & 84.4 & 67.5 \\
$2004-05$ & 73.2 & 26.3 & 21.9 & 96.7 & 59.4 & 85.0 & 70.2 \\
\hline
\end{tabular}

Source: Commonwealth Department of Health and Aged Care, 2004.

Figure 3: GP Schedule Fee in constant prices and as a proportion of consultations bulk billed 1984-85 to 2000-01

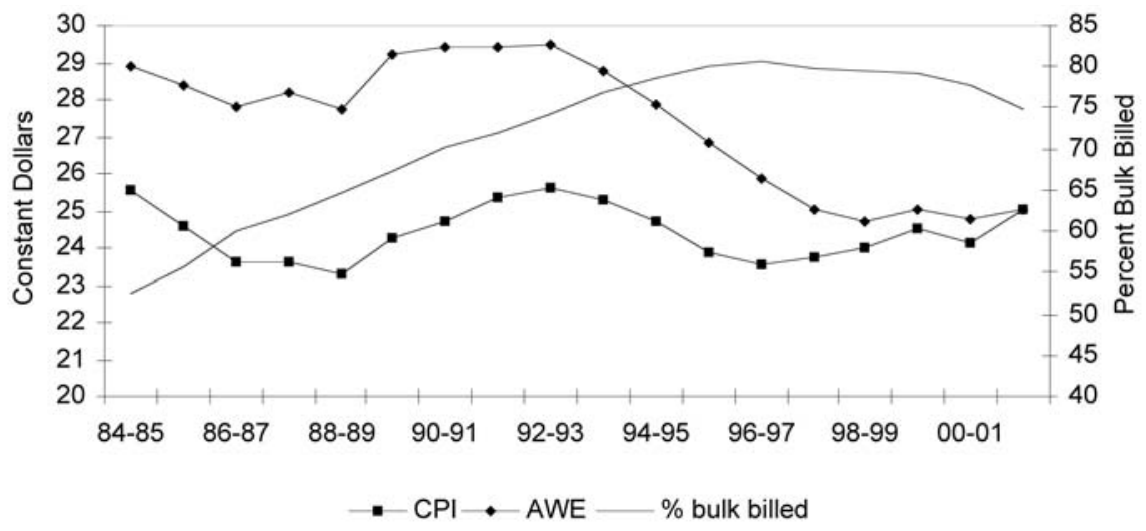

Source: Data supplied by lan McAuley, University of Canberra.

\subsection{A Fairer Medicare/Medicare Plus}

The Howard government's 2003 Fairer Medicare package revived and extended the failed attempt by the Hawke government to impose co-payments for bulk-billed services. In addition, Fairer Medicare proposed differential rebates (higher for concession card holders and non metropolitan residents), a safety net to limit out-of-pocket expenditure by providing rebates to concession card holders and access to PHI for others.

Following rejection in the Senate, the government launched a revamped Medicare Plus package which was further amended. The safety net meant that 80 per cent of out-of-pocket expenses were reimbursed after expenditure of $\$ 300$ per annum for concession card holders and families receiving Family Tax Benefit A, and \$700 for others. The proposal to permit PHI to cover out-of-pocket expenses was scrapped and the additional bulk-billing rebate was increased from $\$ 5$ to $\$ 7.50$ for country areas and Tasmania. In addition, patients with extended care plans gained access to up to 5 consultations with allied health professionals including psychologists, physiotherapists, podiatrists, dietitians, and up to 3 dental visits. Workforce shortages resulting from 
previous government policy decisions were partially addressed by additional medical school and GP registrar places and funding was provided for nurses in GP surgeries. Subsequently, the Medicare rebate was increased to 100 per cent of the Schedule fee in 2005 but safety net thresholds increased to $\$ 500$ for concession card holders and $\$ 1000$ for others. Safety net expenditure, forecast to cost $\$ 440$ million over 4 years, ballooned to $\$ 280$ million in 2005 and was concentrated in higher socio-economic areas.

\subsection{Pharmaceutical Benefits Scheme (PBS)}

PBS expenditure increases are attributed to expensive new drugs, increasing numbers of older persons with chronic conditions, preventative medicine, national health awareness campaigns, an increasing proportion of concessional patients, and cost-shifting from the States (Rickard, 2002). Between 1974-75 and 2003-04 PBS expenditure increased from $\$ 329$ million to $\$ 6.5$ billion and patient contributions increased from \$67 million to $\$ 937$ (Department of Health and Ageing, 2004).

Major policy measures since 1984 have been: restrictions on listing drugs on the PBS, use of monopsony power to control prices, and increasing co-payments. Cost containment attempts have included measures to minimise price differences with generic drugs, delisting of over the counter medicines, price volume agreements, and establishment of the Economics Sub-Committee (ESC) of the Pharmaceutical Benefits Advisory Committee in 1993 to conduct economic evaluations prior to listing on the PBS.

Prescription costs doubled in 1986 and access to free prescriptions for pensioners was abolished in 1990. Subsequently, payments and safety net amounts have been increased, although this has sometimes been challenged in the political arena; notably higher prescription prices were delayed in the Senate for over two years before being implemented in 2005. Higher co-payments have been criticised for potential adverse health outcomes resulting from decreased consumption, particularly by low income earners (Metherell, 2004; Sperling and Parslow, 1999: 25). In the first three months after higher co-payments commenced in January 2005, the number of prescriptions filled dropped to 42 million from 44 million the previous year, particularly affecting drugs for treating cholesterol and high blood pressure.

\section{Conclusion}

The two major trends in the Australian health system over the past two decades have been increased private provision and a shift in the funding burden to individuals. The increased private sector share of hospital provision resulted from public sector funding constraints and the opening up of the public hospital sector to profit-making businesses through outsourcing and PPPs. Individuals have incurred increased health costs as a consequence of restricted access to bulk-billing and increasing reliance on private hospitals.

As with other areas of the welfare state, the totality of Medicare developments since 1984 constitutes a movement toward a more residual system where access to services is increasingly market determined. Segregation of the population into welfare recipients and the self-sufficient constitutes a two-tier system that jeopardises equity outcomes. Although they have always had inferior access to health services due to flaws in the Medicare system, low income Australians without PHI now face further deterioration in 
timely access to necessary treatment. Moreover, the outcome of the ideological assault on the Medicare objective of providing universal coverage for medical care and free access to public hospital treatment free of charge will have repercussions for the future. If the expectation of self-reliance becomes widely accepted in the Australian community it will undermine community support for equitable access to medical treatment as a right of citizenship and provide a basis for future retrenchment.

\section{References}

Auditor General (2000) "Private Care for Public Patients: A Follow-on Examination of the Joondalup Health Campus Contract", Report No. 4 June 2000, Perth, Western Australia, Auditor General.

Australian Institute of Health and Welfare (2003) National health expenditure, current prices 1960-61 to 2001-02, viewed 24 February 2004, available at http://www.aihw. gov.au/expenditure/datacubes/index.html.

Australian Institute of Health and Welfare (2004) Australian Hospital Statistics 2002-03, AIHW cat. no HSE 32, Health Services Series no. 22, AIHW, Canberra.

Collyer, F. (1997) "Privatisation and the Public Purse: The Port Macquarie Base Hospital”, Just Policy, No. 10, pp. 27-47.

Commonwealth Department of Health and Aged Care (2004) Medicare Statistics, viewed 12 October 2004, available at http://www7.health.gov.au/haf/medstats/ tableb7.xls.

Deeble, J. (2002) "Funding the essentials: the Australian Health Care Agreements, 2003-2008”, Australian Health Review, Vol. 25, No. 6, pp. 1-7.

Deeble, J. (2003) "The private health insurance rebate", Report to State and Territory Health Ministers, National Centre for Epidemiology and Population Health, Canberra, The Australian National University.

Department of Health and Ageing (2004) Pharmaceutical Benefits Scheme - History, 1948-49 to 2003-04, viewed 5 April 2005, available at http://www.health.gov. $\mathrm{au} /$ internet/wcms/publishing.nsf/Content/health-pbs-general-pubs-pbbexp-jun04. htm/\$FILE/bookp36.pdf.

Donato, R. and Scotton, R. (1998) “The Australian health care system”, In Economics and Australian Health Policy, (Eds, Mooney, G. and Scotton, R.) Allen and Unwin, St Leonards, NSW, pp. 20-39.

Duckett, S. J. and Jackson, T. J. (2000) "The new health insurance rebate: an inefficient way of assisting public hospitals", Medical Journal of Australia, 172, pp. 439-442.

Faux, J. and Mishel, L. (2000) "Inequality and the Global Economy", In On the Edge: Living with Global Capitalism, (Eds, Hutton, W. and Giddens, A.), London, Jonathan Cape, pp. 93-111.

Hall, J. (2001) "The public view of private health insurance", Commissioned Paper Series 2001/04, Sydney, Australian Health Policy Institute.

Harding, J. (2000) "The supply and distribution of general practitioners", In General Practice in Australia: 2000, (Ed, Commonwealth Department of Health and Aged Care) Canberra, Commonwealth Department of Health and Aged Care, pp. 41-73. 
Hirst, P. and Thompson, G. (1999) Globalization in Question: the international economy and the possibilities of governance, Malden, MA, Blackwell.

Howard, J. (2001) Address at the Federal Liberal Party campaign launch, Sydney 28 October 2001, viewed 14 May 2003, available at http://www.pm.gov.au/news/ speeches/2001/speech1311.htm.

Industry Commission (1997) "Private Health Insurance", Report No. 57, Canberra, Australian Government Publishing Service.

McAuley, I. (1999) "Public funding: Good Social Policy - Good Economics", Address to the Queensland Nurses' Union Conference, July 1999.

McAuley, I. (2003) "Funding health care - taxes, insurance or markets?" Health Insurance Summit, Sydney, 13-13 June 2003.

McAuley, I. (2005) "Private Health Insurance: Still Muddling Through”, Agenda, Vol 12, No 2, pp. 159 -178.

Metherell, M. (2004) Call to stagger rise in cost of prescription drugs, Sydney Morning Herald, 20 August 2004, Sydney.

National Health Strategy (1991) "Hospital services in Australia access and financing", Issues Paper No. 2, Melbourne, National Health Strategy.

OECD (2003) "Private Health Insurance in Australia: A Case Study", OECD Health Working Papers No. 8, Paris, OECD.

Pierson, P. (1994) Dismantling the Welfare State? Regan, Thatcher and the Politics of Retrenchment, Cambridge, Cambridge University Press.

Public Health Insurance Administration Council (PHAIC) (2003) Statistical trends in membership and benefits, viewed 25 February 2004, available at http://www. phiac.gov.au/statistics/trends/index.htm.

Richardson, J. (2003) "Financing Health Care: Short Run Problems, Long Run Options", Health Economics Unit, Centre for Health Program Evaluation, Melbourne, Monash University.

Rickard, M. (2002) The Pharmaceutical Benefits Scheme: Options for Cost Control, Current Issues Brief no. 12 2001-02, viewed 11 April 2005, available at http://www. aph.gov.au/library/pubs/CIB/2001-02/02cib12.htm.

Ross, B., Snasdell-Taylor, J., Cass, Y. and Azmi, S. (1999) "Health Financing in Australia: The Objectives and Players", Occasional Papers: Health Financing Series Volume 1, Canberra, Department of Health and Aged Care.

Scotton, R. B. and Macdonald, C. R. (1993) The making of Medibank, School of Health Services management, Kensington, University of New South Wales.

Senate Select Committee on Medicare (2003a) Medicare, Official Committee Hansard, Wednesday, 30 July 2003, Adelaide, Canberra, Commonwealth of Australia.

Senate Select Committee on Medicare (2003b) Medicare, Official Committee Hansard, Tuesday, 23 September 2003, Canberra, Commonwealth of Australia.

Shaoul, J. (2003) "Global Capital and Healthcare Reform: the Experience of the UK", In Restructuring Health Services: Changing contexts and comparative perspectives, (Ed, Sen, K.), London, Zed Books, pp. 146-159. 
Spencer, J. and Harford, J. (2003) Submission to The Senate Select Committee on Medicare, viewed 16 March 2006, available at http://www.aph.gov.au/Senate/ committee/medicare_ctte/fairer_medicare/submissions/sub212.doc.

Sperling, P. and Parslow, R. (1999) "Public and Private - In Partnership for Australia's Health”, Occasional papers: Health Financing Series Volume 4, Canberra, Commonwealth Department of Health and Aged Care.

The Howard Government (2001) Our future action plan: A Healthier Australia, viewed 16 April 2004, available at http://www.liberal.org.au/documents/health.pdf. 